\title{
A Single Center's Experience With Donation of Facial Allografts for Transplantation
}

\section{Citation}

Huang, Anne. 2018. A Single Center's Experience With Donation of Facial Allografts for Transplantation. Doctoral dissertation, Harvard Medical School.

\section{Permanent link}

http://nrs.harvard.edu/urn-3:HUL.InstRepos:41973459

\section{Terms of Use}

This article was downloaded from Harvard University's DASH repository, and is made available under the terms and conditions applicable to Other Posted Material, as set forth at http:// nrs.harvard.edu/urn-3:HUL.InstRepos:dash.current.terms-of-use\#LAA

\section{Share Your Story}

The Harvard community has made this article openly available.

Please share how this access benefits you. Submit a story.

Accessibility 
Scholarly Report submitted in partial fulfillment of the MD Degree at Harvard Medical School

Date: 18 February 2018

Student Name: Anne Huang, BS

Scholarly Report Title: A Single Center's Experience with Donation of Facial Allografts for Transplantation

Mentor Name(s) and Affiliations: Ericka M Bueno, $\mathrm{PhD}$ and Bohdan Pomahac, MD from the Department of Surgery, Division of Plastic Surgery at Brigham and Women's Hospital

Collaborators, with Affiliations: None 


\begin{abstract}
Title: A Single Center's Experience with Donation of Facial Allografts for Transplantation
\end{abstract}

Authors: Anne Huang, Ericka M Bueno, Bohdan Pomahac

Purpose: Face transplantation offers superior functional and aesthetic outcomes when compared with conventional reconstruction. Optimizing criteria to match donors and recipients will improve outcomes. However, there is limited available literature regarding donor procurement and matching.

Methods: The Brigham and Women's Hospital describes its experience with facial allograft donation for 7 face transplants performed between 2009 and 2014. Important considerations include donors' type of death, allograft ischemia time, demographics, immunologic compatibility, serology, and donor facial restoration.

Results: Brain-dead, heart-beating donors were preferred because their hemodynamic stability facilitated procurement logistics. The maximum allograft ischemia time allowed by our team was 4 hours. Donor and recipient should be matched in appearance by having the same gender, similar age, and comparable skin tone/texture. Immunologic compatibility requires ABO compatibility, suitable HLA typing, and negative crossmatch. Donor serology for infectious diseases, especially cytomegalovirus (CMV) and Epstein-Barr virus (EBV), is important because of implications of post-transplant immunosuppression. High-risk CMV and EBV matches (donor-positive/ recipientnegative) should be avoided when possible. Facial restoration with a prosthetic mask was performed to preserve the donor's dignity.

Conclusions: Although every face transplant recipient has unique needs, the authors hope that sharing their institution's experience with facial allograft donor characteristics will help other face transplant centers and guide future regulation of facial composite allograft donation. 


\section{Description of Student Contribution}

My scholarly project is a retrospective, descriptive study of the seven face transplants performed at the Brigham and Women's Hospital (BWH) between 2009 and 2014, with the objectives of:

1. Studying which characteristics were used in evaluating and matching potential donors and recipients, and how these matches affected recipient outcomes

2. Examining the logistics of donor procurement

3. Using the BWH experience to recommend a set of donor selection principles

I was responsible for literature review, data collection, data analysis and interpretation, and primary drafting of a poster that was presented at a conference and this manuscript. Dr. Pomahac and Dr. Bueno provided mentorship and guidance throughout the project, and helped to formulate the initial idea for this project. For the literature review, I culled full text articles from several databases, including PubMed, Cochrane Database of Systematic Reviews, Medline, and Embase. Key words and phrases included "face transplantation," "face allograft," "donor," "donation," and "procurement." I first screened articles using their titles and abstracts before screening the full text. Reasons for exclusion included articles that do not describe donor characteristics or logistics of procurement. I then identified relevant information about donors and recipients from previously collected data from the archives of the BWH face transplant program. Finally, I synthesized these findings from the BWH experience to recommend a set of donor selection principles. I was the primary author and wrote the majority of the manuscript, with edits from Dr. Bueno and Dr. Pomahac. Dr. Bueno helped with submission and revision of the manuscript.

Citation of published work: Anne Huang, Ericka M. Bueno \& Bohdan Pomahac (2015) A Single Center's Experience with Donation of Facial Allografts for Transplantation, Vascularized Composite Allotransplantation, 2:4, 80-87, DOI:

$10.1080 / 23723505.2016 .1189992$

Link to published work: http://dx.doi.org/10.1080/23723505.2016.1189992 


\title{
A Single Center's Experience with Donation of Facial Allografts for Transplantation
}

\author{
Anne Huang, BS, Ericka M Bueno, PhD, and Bohdan Pomahac, MD* \\ Department of Surgery; Division of Plastic Surgery; Brigham and Women's Hospital; Harvard Medical School; Boston, MA USA
}

Keywords: face transplantation, organ donation

\begin{abstract}
Abbreviations: BMI, body mass index; BWH, Brigham and Women's Hospital; CMV, cytomegalovirus; EBV, Epstein-Barr virus; HLA, human leukocyte antigen; IRB, institutional review board; NEOB, New England Organ Bank; OPO, organ procurement organization; PRA, peak reactive antibodies; UNOS, United Network for Organ Sharing; VCA, vascularized composite allotransplantation
\end{abstract}

Face transplantation offers superior functional and aesthetic outcomes when compared with conventional reconstruction. Optimizing criteria to match donors and recipients will improve outcomes. However, there is limited available literature regarding donor procurement and matching. The Brigham and Women's Hospital describes its experience with facial allograft donation for 7 face transplants performed between 2009 and 2014. Important considerations include donors' type of death, allograft ischemia time, demographics, immunologic compatibility, serology, and donor facial restoration. Brain-dead, heart-beating donors were preferred because their hemodynamic stability facilitated procurement logistics. The maximum allograft ischemia time allowed by our team was 4 hours. Donor and recipient should be matched in appearance by having the same gender, similar age, and comparable skin tone/texture. Immunologic compatibility requires ABO compatibility, suitable HLA typing, and negative crossmatch. Donor serology for infectious diseases, especially cytomegalovirus (CMV) and Epstein-Barr virus (EBV), is important because of implications of post-transplant immunosuppression. High-risk CMV and EBV matches (donor-positive/ recipient-negative) should be avoided when possible. Facial restoration with a prosthetic mask was performed to preserve the donor's dignity. Although every face transplant recipient has unique needs, we hope this report will help identify important donor characteristics that can be incorporated in a national donor registry.

\section{Introduction}

Vascularized composite allotransplantation (VCA) is a revolutionary advance in reconstructive surgery. ${ }^{1,2}$ It consists of transferring functional anatomic units such as the face or limbs from a deceased donor to a recipient needing functional restoration. Compared with conventional reconstruction, facial allotransplantation offers superior functional and aesthetic outcomes thus improving social reintegration and quality of life in patients with severely disfiguring injuries. ${ }^{3-5}$

The first face transplant in the world was performed in $2005 .^{6}$ To date, more than 30 cases have been reported worldwide. ${ }^{7}$ Our institution has performed 7 of these operations since 2009. With increasing clinical experience, we have observed the importance of optimizing criteria for matching donors with recipients, in order to improve treatment outcomes and, in the long term, possibly facilitate consent to facial allograft donation.
There is limited available literature regarding donor procurement/matching in face transplantation. ${ }^{8,9}$ Here, we describe the experience of the Brigham and Women's Hospital (BWH) with 7 cases of donor facial allograft procurement/ matching. We hope this report will contribute necessary information to eventually establish donor characteristics that can be incorporated in a national VCA donor registry. $^{10,11}$

\section{Single Center Experience}

Our guidelines for facial donor matching include matched gender, approximate age, similar skin tone and texture, compatible blood group, suitable HLA typing, and location at most 1-2 hours away by commercial flight or 2 hours by land. We collaborate with the local organ procurement organization (OPO), the New England Organ Bank

(c) Anne Huang, Ericka M Bueno, and Bohdan Pomahac

*Correspondence to: Bohdan Pomahac, MD; Email: bpomahac@partners.org

Submitted: 03/16/2016; Revised: 05/08/2016; Accepted: 05/11/2016

http://dx.doi.org/10.1080/23723505.2016.1189992

This is an Open Access article distributed under the terms of the Creative Commons Attribution-Non-Commercial License (http://creativecommons.org/ licenses/by-nc/3.0/), which permits unrestricted non-commercial use, distribution, and reproduction in any medium, provided the original work is properly cited. The moral rights of the named author(s) have been asserted. 
(NEOB), which identifies potential donors and approaches their families to request consent. In the most recent 3 cases, we also worked with Lifebanc, the OPO covering Northern Ohio. After the OPO obtains consent from the donor's family, our team of surgeons travels to the donor's institution and recovers the facial allograft, typically before the recovery of solid organs, in order to minimize ischemia time. Our team also typically recovers a radial forearm flap to be transplanted into an inconspicuous location of the recipient's body and used as a sentinel site for monitoring allograft rejection. We have found that the histopathological grade of rejection in these sentinel flaps reliably correlates with facial allograft skin biopsies, particularly during severe rejection episodes. $^{28}$

The facial allograft is then flushed, packed on ice slurry, and transported to the recipient's operating room.

We describe each case below, with donor and recipient characteristics detailed in Table 1 and notable aspects of the donor procurement operation in Table 2.

Patient 1. Our team sought a partial face and forearm graft (sentinel graft) donor for a 59 year-old man that had sustained electrical burn injuries $4 \mathrm{y}$ prior to presentation. The facial allograft needed to include zygomatic and maxillary bones, right and left cheeks, teeth, nasal cartilage, muscles of facial animation, facial and buccal nerves, and accompanying vessels. After a 3 month wait, a donor became available and the patient received a partial face transplant in April 2009. The donor was a 60 year-old man who suffered a cerebrovascular accident during heart transplant surgery (embolism). Although of different ethnicities, donor and recipient had similar skin tone/texture. Of note, the donor was CMV seropositive and the recipient was CMV seronegative. The patient understood and accepted the risks of using a CMV seropositive donor. Prophylactic treatment, onset of CMV viremia, treatment, and resolution are described in Table 3.

This donor was located at BWH and therefore our leading surgeon was able to evaluate him in person. The facial allograft was procured in an operating room adjacent to the recipient's in a 6-hour operation with no noted complications. A silicone mask fabricated by our team's anaplastologist was positioned over the donor's facial defect for the preservation of dignity. The donor's family and recipient have corresponded and met in person on several occasions; they have been publicly identified and spoken positively to the media about their experiences. In addition, the donor's wife has written a book describing this experience. ${ }^{12}$

Patient 2. Our team sought a facial and forearm graft donor for a 25 year-old man who sustained electrical burn injuries 3 y prior to presentation. We expected increased difficulty finding an immunologically compatible donor because this patient was highly sensitized (peak Panel Reactive Antibodies of 68\%). After 6 months, a 48-year old donor was found. Given the age mismatch, our patient had the option of declining and waiting for a younger donor.
However, he elected to proceed and received a full face transplant in March 2011.The facial allograft procurement operation was uneventful until the abdominal organ recovery team requested an earlier cross-clamping time. Thus, the last 2 hours of the operation were completed under cold ischemia. The patient and the donor's family have corresponded through the OPO.

Patient 3. We sought an allograft including nose and surrounding skin, upper and lower eyelids, forehead, full thickness lower lip and tissues in the submandibular region for a 30 year-old man who sustained electrical burn injuries 10 y prior to presentation. After a 4 month wait, a donor was found in April 2011. Facial allograft procurement was uneventful. Serology mismatch between donor and recipient resulted in post-transplant primary CMV infection (Table 3). The donor's family and recipient met shortly after the transplant and continue to stay in contact.

Patient 4. We sought a donor of both face and bilateral hands for a 56 year-old woman attacked by an animal 2 y prior to presentation. The attack resulted in below-theelbow amputation of the patient's left arm and right digits 2 through 5 in addition to the facial defects. After 3 months, a donor was found and the patient received full face and bilateral hand transplants in May 2011. The face transplant team had to wait an extra 1.5 hours for the 2 upper extremity recovery teams to finish procurement, because only 2 microscopes fit simultaneously in the operating room. After transplant, the recipient has communicated with the donor's family confidentially.

Patient 5. A 44 year-old woman had sustained chemical burns over $80 \%$ of her body in a domestic violence assault in 2009. The patient had multiple risk factors for developing anti-HLA antibodies, including 2 pregnancies, multiple transfusions following the burn injury, and several surgeries. Therefore, she had a high degree of sensitization and was likely incompatible with most potential donors (peak PRA of $98 \%$ ). In order to expand the chances of matching her with a donor, we sought to find a compatible donor of full facial and forearm grafts within a wide age range (1863 years). The patient waited 14 months on the transplant list, during which there were several incompatible donor notifications. In February 2013 we were notified of a potential donor, but complement-dependent cytotoxic crossmatch came back positive for $\mathrm{T}$ cells (and negative for B cells). Traditionally, such a positive crossmatch would be a contraindication to solid organ transplantation. ${ }^{13}$ However, we deemed the positive crossmatch acceptable in this particular case, given the patient's high sensitization, low likelihood of finding a more suitable donor in the future, and the recent implementation of a desensitization protocol in our study design. We planned to treat high level of antibodies post operatively with a combination of modalities including a plasmapheresis protocol that had been used at BWH for living donor kidney transplant recipients for over 10 y and was approved by our IRB. We discussed with the patient that the risks of failure were 


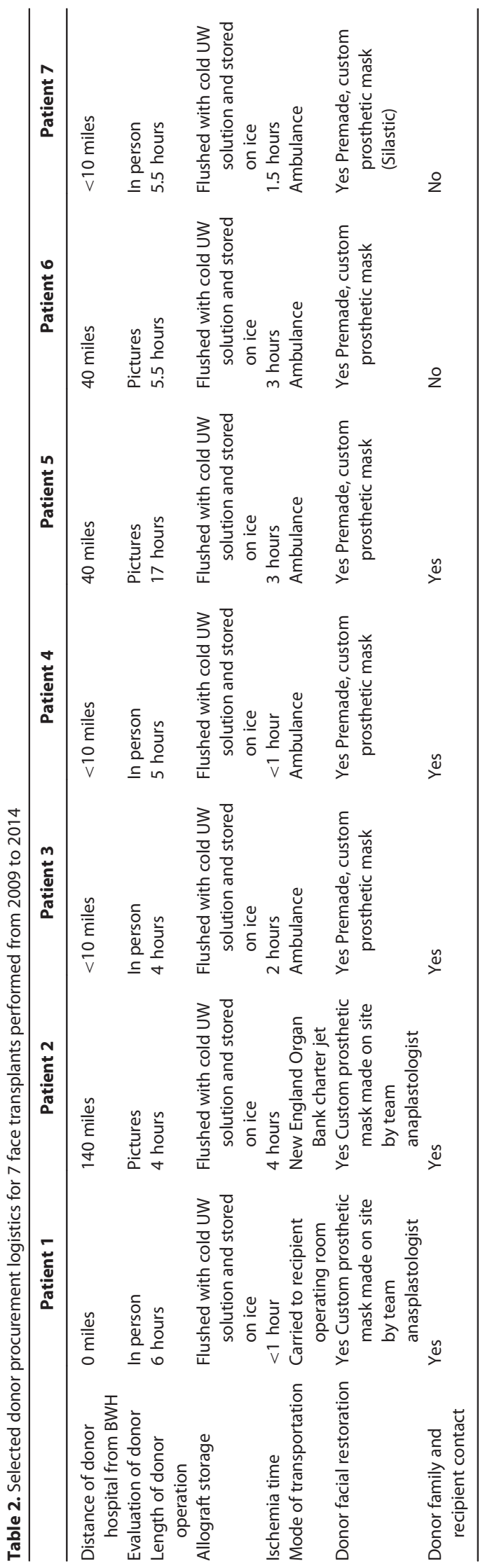


Table 3. Post-transplant primary CMV infection in 3 face transplant recipients

\begin{tabular}{|c|c|c|c|}
\hline & Patient 1 & Patient 3 & Patient 6 \\
\hline Prophylactic treatment & $\begin{array}{l}\text { Valganciclovir, } 900 \mathrm{mg} / \text { day for } \\
1 \text { year }\end{array}$ & $\begin{array}{l}\text { Valganciclovir, } 900 \mathrm{mg} / \text { day for } \\
7 \text { months }\end{array}$ & Valganciclovir, $900 \mathrm{mg} /$ day for 6 months \\
\hline Post-operative month of onset & 15 months & 7 months & 6 months \\
\hline Symptoms & $\begin{array}{l}\text { CMV viremia (viral load 21,400 } \\
\text { copies } / \mathrm{mL} \text { ) }\end{array}$ & $\begin{array}{l}\text { Epigastric pain, nausea, and vomiting } \\
\text { CMV gastritis CMV duodenitis CMV } \\
\text { viremia ( } 144,000 \text { copies } / \mathrm{mL})\end{array}$ & $\begin{array}{l}\text { CMV viremia }(30,000 \text { copies } / \mathrm{mL}) \text { Guillain- } \\
\text { Barré syndrome }\end{array}$ \\
\hline Treatment & $\begin{array}{l}\text { Valganciclovir, } 900 \mathrm{mg} / \mathrm{BID} \text { for } \\
3 \text { months }\end{array}$ & $\begin{array}{l}\text { Valganciclovir, } 900 \mathrm{mg} / \mathrm{BID} \text { for } \\
3 \text { months }\end{array}$ & $\begin{array}{l}\text { Valganciclovir, } 900 \mathrm{mg} / \mathrm{BID} \text { for } 2 \text { months } \\
\text { Foscarnet, IV BID for } 2 \text { months } \\
\text { Valganciclovir, } 500 \mathrm{mg} / \mathrm{BID}\end{array}$ \\
\hline Resolution & Yes & Yes & No \\
\hline Recurrence & No & No & Yes \\
\hline
\end{tabular}

higher as a result of the positive crossmatch, and the patient accepted these risks.

Of note, in this case we intended to procure at least one of the donor's ears, but were unable to do so because of scars in the preauricular area from a facelift. Despite this challenge, we continued with facial allograft recovery because the recipient's high PRA made it unlikely that another suitable donor would be found. After uneventful procurement and transplant operations, our patient exhibited signs of acute rejection which was deemed antibody-mediated and a first of its type in face transplantation. ${ }^{14}$ The patient was treated with combination therapy of plasmapheresis, eculizumab, bortezomib, and alemtuzumab. By six months post-transplant, there were no histological signs of rejection. Although antibody-mediated rejection was difficult to manage in this patient, there have been few rejection episodes since and they all have been cell-mediated and easily manageable. The donor's daughter and the patient have met and spoken together publicly at a few organ donation events.

Patient 6. We sought a donor of central face tissues including the nose, lips, and upper and lower jaw as well as forearm graft, aged 15-55 y for a 38 year-old male who sustained gunshot wound to the face $14 \mathrm{y}$ prior to presentation. Eleven months later, a donor was found and the patient received partial face transplant in March 2014. There was a mismatch in donor/recipient (+/-) CMV serology, and subsequent CMV viremia (Table 3). CMV was resistant to ganciclovir, cidofovir, and foscarnet treatment. The patient has since experienced recurrent episodes of CMV viremia and acute, cellular rejection. His CMV infection has also been associated with an episode of Guillain-Barré Syndrome that resolved through 4 sessions of intravenous immunoglobulin $(0.5 \mathrm{mg} / \mathrm{kg})$ and transitioning from tacrolimus to sirolimus. To the best of our knowledge, there has been no contact between the donor's family and recipient.

Patient 7. We sought an allograft containing the central face tissues, including the nose, lips, and upper and lower jaw for a 33 year-old man who sustained gunshot wound to the face in 2012. As procurement of VCAs became officially regulated by UNOS in 2014, this was also the first patient added by our team to the UNOS database. We requested a face and forearm graft donor aged between 15 and 47 y. A donor was found after 11 months, in October 2014. Notably, this donor's hands were simultaneously procured for a patient who received bilateral upper arm transplant also at our institution. This donor donated the most organs in the history of organ donation. To date, there has been no contact documented between the donor's family and recipient.

\section{General Considerations}

\section{Types of donors}

Although our team considers both brain-dead (heartbeating) and donation-after-cardiac-death donors, only heart-beating donors have been used to date. Heart-beating donors are highly preferred because their hemodynamic stability facilitates the logistics of donor procurement. ${ }^{9}$ For instance, with a heart-beating donor there is more time to mobilize donor and recipient surgical teams, the donor team can work before the arrival of other organ procurement teams, and there is better control of total allograft ischemia time.

\section{Allograft ischemia time}

Several studies have shown that skeletal muscle has poor ischemic tolerance. ${ }^{15-18}$ Irreversible muscle cell damage may begin as early as after 3 hours of ischemia, and complete damage may occur at 6 hours, although exact time frames are subject to debate. ${ }^{16}$ The maximum ischemia time presently allowed by our team is 4 hours, defined as the time from cross clamping to re-anastomosis. This limitation on ischemia time is not absolute, but our team prefers to minimize ischemia time as much as possible because facial composite allografts have a large muscle component. Other teams have reported successful face transplantation procedures with ischemia times of 4 hours or less. ${ }^{6,19,20}$ To stay within this ischemia time frame, we recruit donors within 12 hours of commercial flight and up to 2 hours of land travel. This allows additional time to prepare, flush, package, unpack, and re-anastomose the facial allograft while keeping total ischemia time under 4 hours. Unfortunately, this geographical constraint also greatly limits our pool of potential donors. 


\section{Donor characteristics}

Face transplantation is totally different from solid organ transplantation in that the donor and recipient should be somewhat matched in physical appearance. Specifically, characteristics such as age, gender, ethnicity, skin tone/texture, and body mass index (BMI) should be considered. Tattoos or other unique facial characteristics are unacceptable because they can render the donor identifiable. However, there are no set guidelines on how to optimize the matching of appearance, and our team relies on discretion of the lead surgeons.

We previously suggested that facial allograft donors should be between 20 y younger and 10 y older than recipients. ${ }^{21}$ However, our methods leading to this finding had limited ability to realistically reproduce the aesthetic outcomes of a face transplant. Patient satisfaction with older donors was qualitatively assessed, and all 3 of our recipients who were matched with donors that were $>10$ y older than themselves found the match acceptable based on other appearance-matching criteria and the belief that sensitization may significantly delay finding another match. In the future, a larger donor pool may facilitate closer age matching.

To date, all face transplants worldwide have used gendermatched donors because of sex-specific anthropometrics, skin texture, and the ethics regarding the patient's sense of identity. Nonetheless, cross-gender face transplantation has been investigated and may be feasible if the donor-recipient pair is size matched. ${ }^{22}$

Donor skin tone and texture are assessed by the face transplant team through pictures or in person whenever possible. UNOS transplant listing documentation includes matching criteria based on recipient and donor skin tone as measured by the Fitzpatrick scale.

There are currently no standardized measurements for assessing size match in face transplantation, although they exist for other forms of VCA. ${ }^{23,24}$ Five soft tissue and 3 bony craniofacial measurements correlated with better aesthetic outcomes in virtual models of face transplantation. ${ }^{25,26}$ Large differences in BMI between donor and recipient could theoretically lead to a mismatch of soft tissue measurements and adversely affect aesthetic outcomes. However, this has not been thoroughly studied.

\section{Immunologic compatibility}

Standard compatibility screening for face transplantation is similar to that for solid organs: ABO compatibility, HLA typing, and negative crossmatch. ABO compatibility is necessary to prevent hyperacute graft rejection. In contrast to some solid organ transplants, perfect HLA matching is not necessary in VCA. ${ }^{23}$ Therefore, many of the face transplants performed so far, including all hereby reported, did not have perfect HLA matches. ${ }^{27}$ In general, a positive crossmatch between a potential donor and recipient is a contraindication for transplantation. However, our team's immunologic compatibility criteria has evolved to consider donors with a positive crossmatch in cases where the recipient is highly sensitized, has been waiting for transplant for a long time, has been informed of the higher risk of graft failure and is willing to receive a desensitization protocol. There should also be clear and specific plans to treat rejection and potential graft failure. One of our patients who had a positive $T$ cell complement-dependent cytotoxic crossmatch indeed experienced powerful antibody-mediated rejection in spite of desensitization treatment with plasmapheresis. Extensive treatment resolved the rejection, and fortunately the patient has not experienced any adverse side effects or increased incidence of rejection.

\section{Donor serology}

Infectious diseases are common in face transplantation because of the intense immunosuppression imparted on patients. Specifically, opportunistic infections and infections caused by donor flora can cause significant adverse effects. CMV infection has been documented in face transplantation, especially in high-risk matches (i.e. donor-positive/recipientnegative $)^{29-32}$ Three of our patients had high-risk CMV mismatched donors and experienced primary CMV infection several months after transplant (Table 3). Others have treated CMV infection in face transplant recipients with valganciclovir, foscarnet, or investigational drug CMX001.30,32 EBV is another clinically important infection in immunocompromised patients, with complications such as posttransplant lymphoproliferative disorder and B cell lymphoma. ${ }^{30}$ The first case of EBV-associated smooth muscle tumors in a French face transplant patient was recently described. ${ }^{33}$ All patients in this article were EBV seropositive, and none of them have experienced complications due to EBV reactivation.

Because of the increased risk of CMV and EBV infection, the high-risk matching of seropositive donors and seronegative recipients should be avoided when possible. However, due to the high seroprevalence of CMV and EBV, it can be difficult to find a seronegative donor. The BWH team continues to consider CMV/EBV mismatched donors because compatible organs are scarce in our geographic region. In solid organ transplantation, CMV/EBV mismatched transplants are also performed despite the increased risk of infection. The specific risks and benefits of transplanting a high-risk CMV/ EBV mismatched donor should be considered on an individual basis.

\section{Donor facial restoration}

Procurement of the facial allograft leaves a visible deformity on the donor's body. Although we only recruit donors whose families opt for closed-casket funerals, out of respect to the donor and her family we provide restoration with a prosthetic mask. The masks used on the donors of Patients 1 and 2 were fabricated on site based on impressions of the donors' faces prior to recovery. More recently, we have used generic male and female facial masks made of silicone prefabricated by our team's anaplastologist. We have at least 1 facial prosthesis available for each patient listed in the 
transplant waiting list at any given time. The prosthesis travels with the donor procurement team to the donor's operation site. Because it is not possible to create facial prostheses that perfectly recreate the appearance of the donor's face within the available time, these prostheses are not suitable for open-casket funerals.

\section{New England Organ Bank experience with VCA donor authorization}

Between 2009 and 2014, our team was notified of 32 brain dead donors that were identified with the potential to donate VCAs for our patients in the face transplant waiting list. Four out of 32 donor families (12.5\%) were not approached regarding donation for various reasons at the discretion of the organ bank. Of the 28 families approached, 14 declined VCA donation (50\%): in 8/14 cases where families declined facial donation, donors were registered donors (57\%). Of those who said yes to facial allograft donation, 8/ 14 (57\%) were ultimately used as donors for 9 recipients at our institution. The recipients included 6 patients who underwent full or partial face transplants, 1 who underwent concomitant face and bilateral upper extremities, and 2 that received bilateral upper extremities. Communication between recipients and donors was facilitated in a strictly confidential manner through the NEOB. To date, all of our recipients and donor families who have contacted each other have had positive interactions.

\section{Conclusions}

As face transplantation becomes more common, it is important to evaluate and standardize donor inclusion/ exclusion criteria. The BWH face transplant team continues to evolve its donor inclusion/exclusion criteria according to increasing experience. We favor the recruitment of brain dead, heart-beating donors, which allows easier operational logistics of allograft recovery and remain within the current limitations imposed by allograft ischemic damage. Although we prefer age-compatible donor-recipient matches, we have used donors that are $>10$ y older than the recipient when allograft donors are otherwise scarce, and as long as the recipient is in agreement with the age disparity. In the future, standardized pre-transplant craniofacial measurements may be useful in determining a better aesthetic match between donor and recipient. Our guidelines for immunologic compatibility have evolved to include donors with a positive crossmatch in highly sensitized patients and with a clear and specific plan to address desensitization, rejection, and graft failure. In our experience, high-risk CMV and EBV matches (donor positive/recipient negative) should be avoided whenever possible due to increased risks for infection, but may be considered due to the high seroprevalence of CMV/EBV. Although every face transplant recipient has unique needs, the authors hope that sharing their institution's experience with facial allograft donor characteristics will help other face transplant centers and guide future regulation of facial composite allograft donation.

\section{Disclosure of Potential Conflicts of Interest}

The authors declare no conflicts of interest.

\section{Acknowledgment}

We would like to thank our Patient Coordinator, Lisa Quinn, for managing the information about our facial allograft donors and for coordinating all of the face transplant recipients' long-term care.

\section{Funding}

E. M. B. and B. P. receive partial salary support from a research contract with the United States Department of Defense (\#W911QY-09-C-0216).

\section{Authorship}

A. H. and E. M. B. conceived the study. A. H. researched data, analyzed results, and wrote the paper. E. M. B. and B. P. supervised the analysis and edited the manuscript.

\section{References}

1. Pomahac B, Gobble RM, Schneeberger S. Facial and hand allotransplantation. Cold Spring Harb Perspect Biol 2014; 6(3):1-14

2. Pomahac B, Nowinski D, Diaz-Siso JR, Bueno EM, Talbot SG, Sinha I, Westvik TS, Vyas R, Singhal D. Face Transplantation. Curr Probl Surg 2011; 48 (5):293-357; PMID:21463717; http://dx.doi.org/ 10.1067/j.cpsurg.2011.01.003

3. Pomahac B, Pribaz J, Eriksson E, Bueno EM, DiazSiso JR, Rybicki FJ, Annino DJ, Orgill D, Caterson EJ, Caterson SA, et al. Three Patients with Full Facial Transplantation. N Engl J Med 2012; 366 (8):715-22; PMID:22204672; http://dx.doi.org/ 10.1056/NEJMoa1111432

4. Fischer $S$, Kueckelhaus $M$, Pauzenberger $R$, Bueno EM, Pomahac B. Functional Outcomes of Face Transplantation. Am J Transplant 2015; 15(1):220-33; PMID:25359281; http://dx.doi.org/10.1111/ajt.12956
5. Diaz-Siso JR, Parker M, Bueno EM, Sisk GC, Pribaz JJ, Eriksson E, Annino D, Tullius SG, Pomahac B. Facial allotransplantation: A 3-year follow-up report. J Plast Reconstr Aesthetic Surg. Elsevier Ltd; 2013; 66 11):1458-63

6. Devauchelle $B$, Badet L, Lengelé $B$, Morelon $E$, Testelin S, Michallet M, D'Hauthuille C, Dubernard JM. First human face allograft: early report. Lancet 2006; 368(9531):203-9; PMID:16844489; http://dx. doi.org/10.1016/S0140-6736(06)68935-6

7. Khalifian S, Brazio PS, Mohan R, Shaffer C, Brandacher G, Barth RN, Rodriguez ED. Facial transplantation: the first 9 years. Lancet 2014; 6736 (13):2153-2163

8. Siemionow $M Z$, Gordon CR. Institutional review board-based recommendations for medical institutions pursuing protocol approval for facial transplantation. Plast Reconstr Surg 2010; 126 (4):1232-9; PMID:20885245; http://dx.doi.org/ 10.1097/PRS.0b013e3181ee482d
9. Pomahac B, Papay F, Bueno EM, Bernard S, DiazSiso JR, Siemionow M. Donor Facial Composite Allograft Recovery Operation. Plast Reconstr Surg 2012; 129(3):461e-467e

10. Chong T, Pruett TL. Evolution of Face Transplant. Plast Reconstr Surg 2013; 132(5):1370-2; PMID:24165618; http://dx.doi.org/10.1097/PRS.0b013e3182a489dd

11. Cendales LC, Rahmel A, Pruett TL. Allocation of Vascularized Composite Allografts. Transplant J 2012; 93(11):1086-7; http://dx.doi.org/10.1097/ TP.0b013e31824b073f

12. Helfgot SW, Novak W. The Match: Complete Strangers, a Miracle Face Transplant, Two Lives Transformed. New York, NY: Simon \& Schuster; 2013, 280 p.

13. Tait BD, Süsal $C$, Gebel HM, Nickerson PW, Zachary AA, Claas FHJ, Reed EF, Bray RA, Campbell $P$, Chapman JR, et al. Consensus guidelines on the testing and clinical management issues associated with HLA and non-HLA antibodies in transplantation. Transplantation 2013, 
95(1):19-47; PMID:23238534; http://dx.doi.org/ 10.1097/TP.0b013e31827a19cc

14. Chandraker A, Arscott $R$, Murphy GF, Lian CG Bueno EM, Marty FM, Rennke HG, Milford E, Tullius SG, Pomahac B. The management of antibodymediated rejection in the first presensitized recipient of a full-face allotransplant. Am J Transplant 2014; 14(6):1446-52; PMID:24797454; http://dx.doi. org/10.1111/ajt.12715

15. Eckert $P$, Schnackerz K. Ischemic tolerance of human skeletal muscle. Ann Plast Surg 1991; 26 (1):77-84; PMID:1994817; http://dx.doi.org/10.1097/ 00000637-199101000-00012

16. Blaisdell $\mathrm{F}$. The pathophysiology of skeletal muscle ischemia and the reperfusion syndrome: a review. Cardiovasc Surg 2002 Dec;10(6):620-30; http://dx. doi.org/10.1016/S0967-2109(02)00070-4

17. Muramatsu I, Takahata N, Usui M, Ishii S. Metabolic and histologic changes in the ischemic muscles of replanted dog legs. Clin Orthop Relat Res [Internet]. 1985 Jun; 196:292-9. Available from: http://www. ncbi.nlm.nih.gov/pubmed/3995831

18. Steinau H-U. Major Limb Replantation and Postischemia Syndrome [Internet]. Berlin, Heidelberg: Springer Berlin Heidelberg; 1988. Available from: http://link. springer.com/10.1007/978-3-662-02480-5

19. Barret JP, Gavaldà J, Bueno J, Nuvials X, Pont T, Masnou N, Colomina MJ, Serracanta J, Arno A, Huguet $P$, et al. Full face transplant: the first case report. Ann Surg 2011; 254(2):252-6 PMID:21772126; http://dx.doi.org/10.1097/ SLA.0b013e318226a607

20. Siemionow M, Papay F, Alam D, Bernard S, Djohan R, Gordon C, Hendrickson M, Lohman R, Eghtesad B, Coffman K, et al. Near-total human face transplantation for a severely disfigured patient in the USA. Lancet 2009; 374(9685):2039; PMID:19608265; http://dx.doi.org/10.1016/ S0140-6736(09)61155-7
21. Aflaki P, Nelson C, Balas B, Pomahac B. Simulated central face transplantation: age consideration in matching donors and recipients. J Plast Reconstr Aesthetic Surg 2010; 63(3):283-5; http://dx.doi.org/ 10.1016/j.bjps.2009.08.013

22. Pomahac B, Aflaki P, Nelson C, Balas B. Evaluation of appearance transfer and persistence in central face transplantation: A computer simulation analysis. J Plast Reconstr Aesthetic Surg. Elsevier Ltd; 2010; 63(5):733-8; http://dx.doi.org/ 10.1016/j.bjps.2009.01.078

23. McDiarmid SV, Azari KK. Donor-Related Issues in Hand Transplantation. Hand Clin. Elsevier Inc; 2011; 27(4):545-52; http://dx.doi.org/10.1016/j. hcl.2011.08.007

24. Caterson EJ, Diaz-Siso JR, Shetye P, Junker JPE, Bueno EM, Soga S, Rybicki FJ, Pomahac B. Craniofacial Principles in Face Transplantation. J Craniofac Surg 2012; 23(5):1234-8; PMID:22948648; http://dx. doi.org/10.1097/SCS.0b013e318252d406

25. Wallins JS, Chandawarkar AA, Dobry A, Diaz-Siso JR, Bueno EM, Caterson EJ, Jania C, Hevelone ND, Lipsitz SR, Mukundan S Jr, et al. Craniofacial Measurements of Donors and Recipients Correlate with Aesthetic Outcome in Virtual Face Transplantation. Plast Reconstr Surg - Glob Open 2015; 3(5):e385; PMID:26090275; http://dx.doi. org/10.1097/GOX.0000000000000343

26. Chandawarkar A, Diaz-Siso JR, Bueno EM, Jania CK, Hevelone ND, Lipsitz SR, Caterson EJ, Mukundan S Jr, Pomahac B. Facial appearance transfer and persistence after three-dimensional virtual face transplantation. Plast Reconstr Surg 2013; 132(4):957-66; PMID:23783063; http://dx.doi.org/10.1097/ PRS.0b013e3182a0143b

27. IRHCTT: International Registry on Hand and Composite Tissue Transplantation [Internet]. 2015 [cited 2015 Aug 3]. Available from: https://www.handregis try.com/
28. Kueckelhaus M, Fischer S, Lian CG, Bueno EM, Marty FM, Tullius SG, Pribaz JJ, Murphy GJ, Pomahac B. Utility of sentinel flaps in assessing facial allograft rejection. Plast Reconstr Surg [Internet] 2015 Jan; 135(1):250-8. Available from: http://www.ncbi.nlm nih.gov/pubmed/25255116

29. Gordon CR, Abouhassan W, Avery RK. What is the true significance of donor-related cytomegalovirus transmission in the setting of facial composite tissue allotransplantation? Transplant Proc. Elsevier Inc; 2011; 43(9):3516-20; http://dx.doi.org/10.1016/j. transproceed.2011.08.043

30. Gordon CR, Avery RK, Abouhassan W, Siemionow $M$. Cytomegalovirus and other infectious issues related to face transplantation: specific considerations, lessons learned, and future recommendations. Plast Reconstr Surg 2011; 127 (4):1515-23; PMID:21460660; http://dx.doi.org/ 10.1097/PRS.0b013e318208d03c

31. Broyles JM, Alrakan M, Ensor CR, Khalifian S, Kotton CN, Avery RK, Brandacher G, Lee WP, Gordon CR Characterization, prophylaxis, and treatment of infectious complications in craniomaxillofacial and upper extremity allotransplantation: a multicente perspective. Plast Reconstr Surg 2014; 133(4):543e51e; PMID:24675206; http://dx.doi.org/10.1097/ PRS.0000000000000015

32. Knoll BM, Hammond SP, Koo S, Issa NC, Tullius SG, Baden LR, Pomahac B, Marty FM. Infections Follow ing Facial Composite Tissue Allotransplantation-Single Center Experience and Review of the Literature. Am J Transplant 2013; 13(3):770-9; PMID:23279299; http://dx.doi.org/10.1111/ajt.12013

33. Conrad A, Brunet A-S, Hervieu V, Chauvet $C$ Buron F, Collardeau-Frachon S, et al. Epstein-Bar virus-associated smooth muscle tumors in a composite tissue allograft and a pediatric liver transplant recipient. Transpl Infect Dis 2013; 15 (5):182-6 